\title{
The Utrecht Virtual Learning Environment Project: Improving Educational Partnerships in Multicultural Preschools
}

\author{
Ryanne Francot, Martine Broekhuizen, \\ Paul Leseman \\ Utrecht University, Faculty of Social Sciences
}

\begin{abstract}
The increasing cultural and linguistic diversity in European countries leads to new challenges for current education systems. One important challenge is establishing trustful educational partnerships with parents from diverse backgrounds. This holds especially true for Early Childhood Education and Care centres (ECEC), where parents are introduced to the education system for the first time. The Utrecht Virtual Learning Environment (U-VLO) project is a small-scale project that explores whether an educational digital tool can help to improve the educational partnerships between parents and a preschool in a multicultural environment in the Netherlands. The digital tool in the current study aims at (a) improving the engagement of parents by incorporating parents as important resources for (b) enriching the preschool practices with a cultural and multilingual focus. The current project follows the principles of Design-Based Research and describes the iterative process of designing and implementing the digital tool, together with the preschool (two preschool teachers working in four classrooms) and parents, to collaboratively create intercultural content via the digital tool. These bottom-up implementations, combined with the results of observations and evaluations amongst teachers and parents, show that it is possible to implement a digital tool in the specific local context. However, many factors and prerequisites, both social and technical, need to be taken into account before the tool can impact the existing partnerships. Clear implications for theory and practice focusing on improving educational partnerships in multicultural and multilingual settings for young children, and the use of innovative digital tools herein, are provided.
\end{abstract}

Keywords: educational partnerships, preschools, ICT, intercultural approach, design-based research

European societies experience increasing cultural and linguistic diversity. As a consequence, education systems are faced with new challenges: How can we do justice to this diversity, and how can we ensure equal opportunities for children from diverse backgrounds? One important strategy to combat inequality and to increase inclusiveness in education for all children from various backgrounds, is to strengthen the connections between the child's school and home environment (Bronfenbrenner \& Morris, 2006; Halgunseth, Peterson, Stark, \& Moodie, 2009; OECD, 2015). However, it can be difficult for schools and preschools to communicate with and to actively involve parents who have different cultural and linguistic backgrounds (Bossong \& Keller, 2018; Putnam, 2007). This can be due to language barriers, cultural differences, or insufficient intercultural competences. Therefore, it is important to focus on innovative strategies that can overcome these barriers and possibly support educational partnerships in multicultural preschool environments, hereby using the cultural and linguistic diversity as an educational resource. The current study is part 
60 of the $U$-VLO project, which stands for Utrecht Virtual Learning Environments. In this study, we focus on the educational partnerships between the parents and the preschool in a multicultural environment, and explore whether a digital tool can help to promote this educational partnership.

\section{Introduction}

\subsection{Educational partnerships}

Educational partnership refers to the belief that both the (pre)school and parents are responsible for creating an optimal environment for the learning and development of the child (Christenson, 2004). The aim is to establish meaningful communication and collaboration in which both parties help and support each other to promote the learning and development of children (De Wit, 2005). Although the term educational partnership is becoming increasingly popular in research and practice, previous studies have been more inconsistent in their terminology. Educational partnership, parental involvement, and parental participation are used interchangeably, though each term refers to different parental behaviours and practices. For instance, parental participation is often defined as the involvement of parents in (pre)schools, but this disregards the involvement of parents in children's learning and development in the home environment. Moreover, the term parental involvement suggests that solely parents should take a step towards the school, instead of both taking a step towards each other (Prins, Wienke, \& Van Rooijen, 2013). Several theoretical frameworks show that parental involvement can be considered a multidimensional concept (see for example Epstein's, 1992, 2001, typology or Hoover-Dempsey and Sandler's, 1995 typology). These frameworks often distinguish between the involvement in school and at home, and between different levels of involvement, such as pedagogical involvement, focusing on the child's development, or democratic involvement, focusing on the decision-making at school. It is important to note that parents and preschools fulfil complementary roles because of their different competences, interests, and responsibilities, such as emotional involvement versus professional involvement. However, they share a common interest, namely creating an optimal environment for the child's learning and development, and have not so much an equal but equivalent role in serving this interest (Oostdam \& Hooge, 2013). In the current study, we involved the parents from the start, and called on their cultural and linguistic expertise to collaborate as partners with the teachers (see also Young \& Hélot, 2007).

The importance of an educational partnership between parents and (pre)school can be traced back to the bio-ecological model of Bronfenbrenner (Bronfenbrenner, 1979; Bronfenbrenner \& Morris, 2006). The child's personal development is central in this model and results from the recurrent interactions (i.e. proximal processes) of a child with his or her immediate environments, the so called microsystems, such as 
the family, peer group, and (pre)school classroom. These microsystems are embed-

ded in larger meso-, exo-, macro-, and chronosystems that directly and indirectly influence the child or his or her immediate environment. For optimal development of the child it is essential that there is coherence and continuity between the microsystems, such as the (pre)school and the family context (Rosa \& Tudge, 2013). This coherence requires common aims, shared understandings, and reciprocal actions (Tayler, 2006). When (pre)schools and parents coordinate their practices, they can complement and strengthen each other.

Much research has been conducted on the positive consequences of educational partnerships on individual child outcomes. Supporting vulnerable parents and stimulating parental involvement and participation are seen as important strategies to improve the academic outcomes of children (Brooks-Gunn \& Markman, 2005; Carolan \& Wasserman, 2015; Fan \& Chen, 2001; Lee \& Bowen, 2006; Respler-Herman, Mowder, Yasik, \& Shamah, 2012). A positive relationship between parents and school may stimulate children's self-regulation skills, learning attitude, homework practices, and the educational ambitions (Semke \& Sheridan, 2012). Studies on partnerships with vulnerable or disadvantaged parents have shown that the number of children who have to repeat a class, drop out, or are referred to special education, is lower when these parents are more involved in the education of their child (Barnard, 2004; Semke \& Sheridan, 2012; Temple, Reynolds, \& Miedel, 2000). Other studies have shown that when parents are more involved, this can mitigate the negative influences of poverty, low parental education level, and ethnic minority status on the academic outcomes of children (De Civita, Pagani, Vitaro, \& Tremblay, 2004; Eamon, 2002; Schreiber, 2002). Also for very young children, a good relationship between parents and the (pre)school has a positive influence, especially on the early language and social development of the child (Grolnick \& Slowiaczek, 1994; Hill \& Taylor, 2004; Jeynes, 2005).

\subsection{Challenges for establishing and improving educational partnerships}

Researchers have claimed that parents and school used to be more aligned, but that nowadays discrepancies in their beliefs and practices lead more often to mistrust and non-collaboration (Dusi, 2012). This has several reasons. First, parents are nowadays better informed and more critical, and thus more strongly positioned towards the (pre)school. This might be due to the individualisation of society, the increasing education level of parents, and increased access to information (Oostdam \& Hooge, 2013). Second, most of the European countries experience a large variety of cultures and languages that, moreover, constantly change, a phenomenon for which the term superdiverse society is coined (Meissner \& Vertovec, 2015). As a consequence of this superdiversity, there is less self-evident alignment between parents and schools regarding their educational norms, values, aspirations, and actions. Research focusing on ECEC has shown that early childhood professionals differ significantly from 
62 migrant parents in their values, developmental aspirations, and beliefs (Bossong \& Keller, 2018). Hence, parents perceive differences between the home environment and the school environment, and can choose to withdraw from interactions with teachers (Crozier \& Davies, 2007; Kim, 2009). To restore and strengthen parent-school partnerships, professionals working in these educational settings should acknowledge the diversity in (pre)schools rather than ignoring it, and be responsive to the needs and beliefs of the culturally diverse group of parents. Moreover, it implies that the teachers should acquire or strengthen their intercultural competences in order to cope with the diversity of parents and children (Van Gorp \& Moons, 2014; Michel \& Kuiken, 2014; OECD, 2013; Young, 2014).

When compared to primary education, preschools are facing additional challenges regarding educational partnerships. Preschools are parents' first encounter in their role as parents with the educational system, and for first-generation migrant parents this is often the first contact with the education system of the host country (RimmKaufmann \& Pianta, 2005). Here, an educational partnership is established that may serve as a long-term model for the relationship between parents and school throughout the school career of the child. However, at the start of preschool, parents often do not know what to expect from the preschool or what is expected from them. This makes it hard for parents to initiate the partnership. Moreover, children going to preschools are still very young without strong verbal skills that could support the communication between parents and preschool (e.g., by telling about the day at the preschool). In many countries preschool starts at age 3. In some countries children are entitled from age 1 or before. In the Netherlands, the ECEC system is complex with full-day daycare for 0 to 4-year-olds, universal kindergarten for 4- to 6-year-olds (part of the primary school system) and half-day preschool for $2 \frac{1}{2}$ to 4 -year-olds. The present study focused on the latter system. Furthermore, in the specific context of the Netherlands, children only go the preschool for a limited amount of time (maximum 1.5 to 2 years for ten hours per week). More research on these challenges, and how to overcome them to enhance the educational partnership in preschools, is needed.

\subsection{Digital tools as support}

The research reviewed above shows that good communication between preschool and parents is important. It should be noted that the nature of the communication between parents and schools has changed over the past decades due to new technologies (Palts \& Kalmus, 2015). There are now multiple ways of exchanging information via ICT. Parents often receive e-mails from school, can check the school website, follow the school on social media, are member of a WhatsApp group with the teacher, and can find the academic results of their child in the digital tracking system. Based on these developments, we assume that digital tools can support educational partnerships in various ways.

First, digital tools can support and improve the communication between parents and schools, and especially make it easier for parents to be informed about the 
daily practices of their child (Jewitt \& Parashar, 2011; Kraft \& Rogers, 2014). Grant (2011) examined the experiences with the use of digital tools to enhance the educational partnership in secondary education. She found that both parents, teachers, and children were convinced that digital tools, such as email or text messages, can enhance the communication, since it can take place more regularly and more directly. Moreover, when parents or teachers use digital tools, they report that they use more time to rethink and carefully formulate their question or message (Byron, 2008; Thompson, Mazer, \& Flood Grady, 2015). Blau and Hameiri (2017) have shown that the teacher should initiate the online interactions between the school and the parents: if the teacher is more active via a digital communication tool, parents will also increase their online communication.

Furthermore, digital tools can help to overcome language barriers between parents and schools in a multicultural and multilingual setting (Davies, 2004; Webb, 2006). Many translation apps, such as Google translate, or multilingual apps have been developed that can help to understand each other or to learn another language (Van Laere et al., 2017). Non-verbal aids, such as emoticons, speech messages, and pictures facilitate understanding of the message. Because of the worldwide use of social media, many people are familiar with the features and possibilities of online platforms such as Facebook, which makes it easier to introduce and implement similar platforms, despite language differences.

Finally, given the challenge of understanding other cultures and languages, digital tools can be a source of information to learn about other cultures or to enrich classrooms with intercultural and multilingual practices (in line with Banks, 2015). It has become easy to explore the world with all its cultures, languages, traditions, norms and values, types of food, Holidays, geography, et cetera, from your own classroom using ICT. Professionals in educational settings can use ICT tools to support their intercultural competences, and to reflect upon their attitudes, knowledge, and practices, in order to improve their collaboration with parents. Intercultural and multilingual practices using ICT send off the important message that the preschool accepts and celebrates the pluralism of cultures and languages, focuses on the inclusion of all views and strives to strengthen the relations between the different cultural and language communities (Holm \& Zilliacus, 2009).

Although digital tools seem to have several advantages for supporting partnerships in a multicultural context, it should be noted that the use of digital tools in educational settings has also raised some concerns. For instance, the privacy and safety of the exchanged information by digital tools, especially when young children are involved, is a serious issue (Selwyn, Banaji, Hadjithoma-Garstka, \& Clark, 2011). Furthermore, it is important to pay attention to the knowledge of and the attitudes towards the use of digital tools, both on the part of the parents and the preschool teachers (Hollingworth, Mansaray, Allen, \& Rose, 2011). Preschool teachers' views and attitudes regarding ICT influence the use and implementation of ICT in the classroom. These attitudes themselves are influenced by a range of factors, for instance, years of service, knowledge of ICT, ICT usage at home, confidence in ICT ability, and 
64 completed relevant in-service training (Kerkaert, Vanderlinde, \& Van Braak, 2015; Petrogiannis, 2010). Wang, Hsu, Reeves, and Coster (2014) implemented a professional development programme to improve the ICT practices of secondary school teachers, following a Design Based Research approach. They concluded that teachers can improve their ICT skills, but that it requires a long, thoughtful implementation, an elaborate training, instruction, and evaluation process, the inclusion of all stakeholders, and scaffolded ICT experiences. Furthermore, certain prerequisites are needed when digital tools are implemented, such as devices in both the home (e.g., smartphones, tablets, computers) and preschool environment (e.g. laptops, digital white boards), and stable (and strong) internet connections. Because of these factors, it should be thoroughly explored on beforehand whether digital tools can be implemented in a particular context, and how the stakeholders are expected to respond to the implementation (Plowman, Stevenson, Stephen, \& McPake, 2012).

\subsection{The present study}

Previous research explored the role of digital tools in different educational settings, ranging from preschool to higher education (e.g. Blau \& Hameiri, 2017; Hatzigianni \& Margetts, 2012; Liu, Toki, \& Pange, 2013). However, to the best of our knowledge, this is one of the first studies to focus on the use of digital tools for building educational partnerships in a preschool setting. The present study was set up as Design Based Research to explore whether the educational partnership between parents and a preschool in a highly multicultural urban environment in the Netherlands can be improved by the use of a digital tool. The Design Based approach implies working closely together with the stakeholders (i.e., parents and preschool teachers) in a specific local context, hereby giving a voice to parents from diverse backgrounds. The digital tool had two aims: 1) improving the engagement of parents with the preschool by acknowledging them as an important resource for intercultural instructional content and support to children's multilingual development, while referring to them as a partner; and 2) enriching preschool classroom practices with intercultural content and multilingual support in collaboration with the parent, thereby including and celebrating cultural and linguistic diversity.

\section{Method}

\subsection{Research design}

The overarching methodology used in this study is the design-based research (DBR) approach, which informs design, theory, and practice concurrently through iterative implementations (Hoadley, 2004; Sandoval, 2014). DBR has a different approach than experimental research since it acknowledges the difficulty of ensuring experimental control over factors and interactions between factors in complex field situations. 
It includes theoretical knowledge in concrete actions and materials, involvement of stakeholders and researchers, adjustment to local contexts, and use of repeated formative evaluations based on observation and interviewing (Hoadley, 2004). Its ultimate goal is "to build a stronger connection between educational research and real world problems" (Amiel \& Reeves, 2008, p. 34).

The current study meets the five requirements of a DBR study (Anderson \& Shattuck, 2012): (1) the study is situated in a real educational context; in this case a preschool in a multicultural neighbourhood in the Netherlands; (2) focuses on the design and testing of an intervention; a digital educational tool; (3) adopts a mixed-methods approach to provide better guidance for educational improvement; focus group-studies, content analyses, observations, and a parent survey; (4) involves multiple iterations to test the best design of the intervention; two full iterations were completed; and (5) promotes collaboration between stakeholders; that is, the researcher, practitioners and parents were working closely together to identify general ICT principles and educational partnership principles for the future.

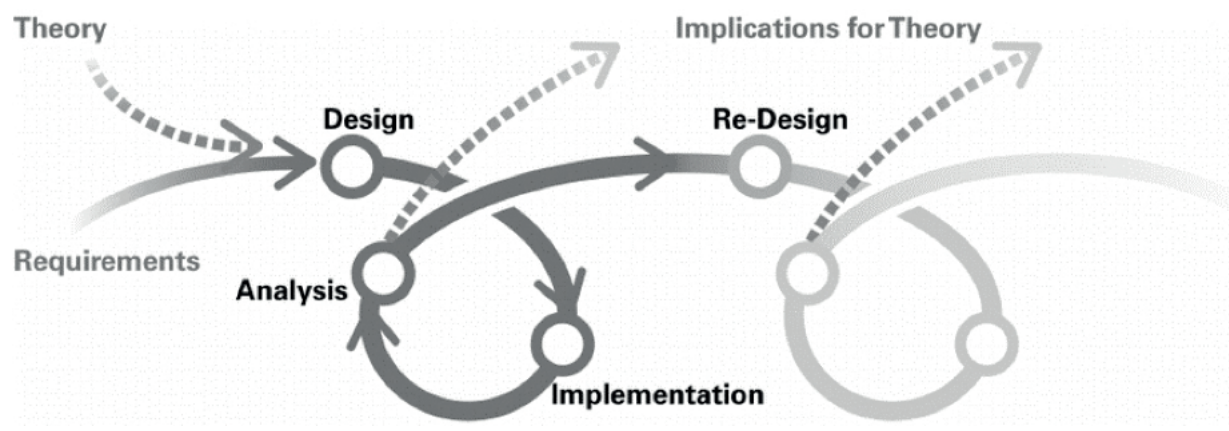

Figure 1 Design-based research approach

\subsection{Procedure}

A preschool in an intercultural neighbourhood in Utrecht, the Netherlands, participated in this study. Table 1 provides the design-based research timeline, including the data collection, divided into four phases. Phase one entailed the exploration and preparation phase. First, a core research team was established - two preschool teachers, two parents and a researcher - who worked closely together during the study. The local context was explored in a focus group session with the core team. After this, a possible digital tool was evaluated together with the core team. Based on this, the first implementation cycle was started and the tool was implemented in the two classrooms where each of the preschool teachers worked. The implementation was observed and documented. This led to further improvement of the implementation and a second cycle in two other classrooms, in addition to the two original classrooms, was started. The second implementation cycle was more successful. Focus groups, classroom observations, content analyses of the posts on 
66 the digital platform and a parent survey were conducted throughout this second implementation. Parents and preschool teachers signed informed consent forms and data were anonymized. The last phase in the DBR approach involved evaluation and reflection to generate design principles for future research, and to provide recommendations for the improvement of educational partnerships for policymakers and practitioners. These design principles and recommendations are summarized in the discussion and conclusion.

Table 1 Time schedule of DBR study

\begin{tabular}{|c|c|c|c|c|c|c|c|c|c|}
\hline & & $\begin{array}{l}\text { Apr - } \\
\text { Jul } \\
2017\end{array}$ & $\begin{array}{l}\text { Sep - } \\
\text { Oct }\end{array}$ & Nov & Dec & Jan & Feb & Mar & $\begin{array}{l}\text { Apr - } \\
\text { May } \\
2018\end{array}$ \\
\hline Phase one & $\begin{array}{l}\text { Exploration and } \\
\text { evaluation of } \\
\text { context with } \\
\text { core team }\end{array}$ & & & & & & & & \\
\hline \multirow{2}{*}{$\begin{array}{l}\text { Phase two (first } \\
\text { implementation } \\
\text { cycle) }\end{array}$} & $\begin{array}{l}\text { Implementation } \\
\text { in two } \\
\text { classrooms }\end{array}$ & & & & & & & & \\
\hline & $\begin{array}{l}\text { Analyses, } \\
\text { evaluation and } \\
\text { redesign for } \\
\text { second iteration }\end{array}$ & & & & & & & & \\
\hline \multirow[t]{2}{*}{$\begin{array}{l}\text { Phase three } \\
\text { (second } \\
\text { implementation } \\
\text { cycle) }\end{array}$} & $\begin{array}{l}\text { Implementation } \\
\text { and data } \\
\text { collection in four } \\
\text { classrooms }\end{array}$ & & & & & & & & \\
\hline & Analyses & & & & & & & & \\
\hline Phase four & $\begin{array}{l}\text { Evaluation and } \\
\text { reflection to } \\
\text { generate design } \\
\text { principles }\end{array}$ & & & & & & & & \\
\hline
\end{tabular}

\subsubsection{Intervention with a digital tool: Padlet}

Given the small scale of this study, it was not feasible to design a new tool. Therefore, the core team explored an existing, though adaptable, digital tool: Padlet. Padlet (www.padlet.com) is a free, multi-device, educational tool. Padlet enables to create an online bulletin board (also called a padlet ${ }^{1}$ ) that can contain messages, photos, audio files, movie clips, presentations, web links, drawings, locations and other files. Collaborators who have access to this padlet (here: parents, teachers and the researcher) can add content, comment upon, like, or edit the content.

1 Note that we use capital letter $\mathrm{P}$ of Padlet when referring to the name of the digital tool, though a small letter when referring to the actual group bulletin boards that have been created during this study. 
Collaborators can have different rights, and the padlet can be password protected. Moreover, the bulletin boards are untraceable for online search engines.

An interactive process between parents and preschool was started via the tool, see Figure 2. As a first step, a group-padlet for the parents and the preschool teacher was created. The parents gave input to the padlet that exposed the cultural and linguistic richness of the families (e.g., pictures, songs, movies, stories, web links, et cetera). Second, this content was used in the classrooms by the teachers to implement intercultural teaching practices. Third, parents received information on these classroom practices and their outcomes via the padlet, so they could continue with these practices in the home environment. By stimulating parents to provide input for the classroom practices that derives from their own cultural and linguistic background, it was hypothesized that the educational partnership would improve.

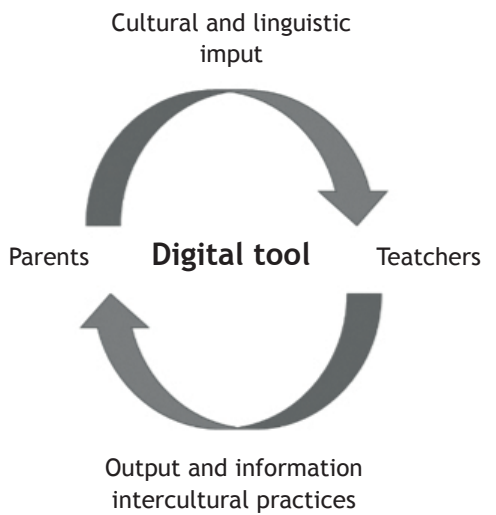

Figure 2 Interaction process with the tool Padlet

\subsection{Participants}

Two preschool teachers (both female), each working in two classrooms (total $n=34$ children in four classrooms), participated in the study. Both teachers have worked in this preschool setting for five to six years. Two parents, one father and one mother, both with a Moroccan background, joined the core team. The preschool has nine classrooms in total, where young children in the age of 2.5 to 4 years old are enrolled for maximum 1.5 year before their transition to kindergarten, which is part of primary education. The children and their parents had diverse backgrounds that mirrored the multicultural composition of the neighbourhood in which the preschool is located: the traditional immigrant groups, such as Turkish and Moroccan families, who originally came to the country as guest workers, expat families, such as Chinese and Indian families, and refugee families from countries such as Syria. 
The study adopted a mixed-methods approach (Tashakkori \& Teddlie, 2006) to collect and analyse the following data: focus group-studies with the core team, content analyses of the use of the digital tool, observations of the use of the digital tool, and a short survey among the parents.

Focus group with core team. The researcher met with the core team approximately every six weeks to evaluate and refine the process. Both the first and the last meeting were guided by semi-structured questions in order to map the multicultural context of the preschool (the first meeting) and to evaluate the study and to generate conclusions and recommendations (last meeting).

Content analyses of Padlet. One month after the second implementation, the content posted on the digital tool was analysed. The extent to which the tool was implemented was examined: to what extent was it used, by whom (teachers and parents), what was the content, and did the content provide intercultural enrichment.

Observation on the use of Padlet. Similar to the content analyses, classroom observations of the use of the group-padlets by the preschool teachers were conducted during the phase three, the second implementation. A semi-structured observation scheme was used (see Appendix A), focusing on the content of the bulletin boards (e.g. What is the focus of the teacher? Is there attention for the cultural diversity in the content?) and on the communication while using the group-padlet (e.g. How is the interaction between the teacher and the children when using the padlet?)

Parent survey. At the start of the second implementation, a short survey was conducted with parents from two classrooms. The goal of the survey was to receive more information on the parents' perspective on the educational partnership and the multicultural richness within the preschool. The survey is based on the structured parent interview study of the ISOTIS project (Broekhuizen, Ereky-Stevens, Wolf, \& Moser, 2018), but adapted together with the core team for this specific DBR study. The survey had three scales with items on (1) the communication and relation with the preschool, (2) parental participation within the preschool, and (3) stimulating activities and language use in the home environment. Furthermore, the degree of attention for their own heritage language and culture at the preschool and parents' feelings about this was assessed with open questions. Parents could fill out the short survey by themselves, since it was available in English, Turkish, Standard-Arabic and Dutch, and included visual aids for the response scales. Parents could also get support from one of the Moroccan-Arabic or Turkish-speaking research assistants that were present during the data collection.

\section{Results}

The results from phase one (the inventory phase), phase two (the first iteration) and phase three (the second iteration and analyses) are described below. The evaluation 
and resulting implications and recommendations (phase four) are described in the discussion and conclusion section.

\subsection{Phase one: Exploration of the context and evaluation tool}

As a first step, an inventory of the local context was conducted through a focus group with the core team. This inventory examined the needs, possibilities, and wishes of the parents and the teachers, in order to ensure that the digital tool and the implementation of the tool were adapted as much as possible to the local context. The most important points from this inventory are discussed below. After the inventory, the digital tool, Padlet, was piloted and evaluated.

Cultural and linguistic diversity. As stated in the method section, the participating preschool has a superdiverse population. Many parents have a low proficiency and use of Dutch and are low educated, especially the mothers. As a consequence, many children do not speak Dutch when they enter the preschool. There is no official intercultural, nor multilingual policy at the preschool. It was stated that Dutch is the main language in the preschool for all children, parents, and teachers. Teachers stressed that this is a daily issue for them; children should learn Dutch, but children should also learn to socialise and express themselves. They acknowledged that when the child does not speak Dutch, it is perhaps better for the child to use the mother language (at least sometimes).

Parents and teachers stated that they were open towards other cultures and that they valued other cultures. Different feasts and holidays were celebrated at the preschool, sometimes also engaging the parents, such as Christmas and Eid al-Fitr. Moreover, some of the preschool teachers had an immigrant background themselves, which facilitated the communication with parents who have similar backgrounds.

Educational partnership. Parents are stimulated to be involved at the preschool in multiple ways. There is a parent board, teachers go on home visits, and there are regular activities and courses for parents (e.g., language courses). During the year, parents have individual talks with the teacher to discuss the progress of their child. Moreover, during the preschool-primary school transition, parents and teachers worked closely together to ensure a smooth transfer for both the child and the parents.

Despite the aforementioned activities, the core team stated that the communication was mostly uni-directional; from the preschool to the parents, and not vice versa. They also experienced language barriers and cultural differences, which sometimes led to frustrations on both sides. According to the teachers, parents were not really engaged in the preschool and many of them did not attend meetings, despite the attempts of the preschool. Parents were usually enthusiastic about the cultural activities that they could celebrate together, but not so much regarding other organized activities, such as creative activities or preschool excursions. 
ICT possibilities. Parents and teachers have a WhatsApp 2 group together, in which photos of activities, general messages, and reminders are shared. Parents stated that they liked the WhatsApp group as an informal way of being updated about the daily activities of their child. However, the direction of communication via WhatsApp was also predominantly from the teachers to the parents. To the knowledge of the core team, all parents have smartphones, but not all parents have access to a tablet or a computer. In addition, the preschool teachers had recently received Digi boards 3 with internet access in their classrooms, which could be used for the current study.

Evaluation of the digital tool Padlet. The Padlet tool was evaluated together with the core team. There were several reasons why we chose to use Padlet. First of all, the app is suitable for Digi boards, smartphones, (laptop) computers and tablets. The tool is also linked to the camera of smartphones, which makes it easier to upload pictures. Second, Padlet creates an interactive platform that stimulates mutual communication and collaboration. Parents and teachers have more or less equal user rights, meaning that they can both upload and comment on the content (though teachers can delete items, parents cannot). The tool scores high on inclusiveness: it is pictorially rather than textually oriented with many colours and pictograms, and people can switch between multiple languages. Another important characteristic is that the group-padlet of each classroom can be secured with personal accounts, accessible only via a password, and that the padlets are not traceable by search engines such as Google. To further ensure security, the core team drafted a contract for the parents, to ensure that nobody would use the uploaded content by other parents outside the padlet, and to stress the ethical aspects of the use of the tool and this study.

\subsection{Phase two: First implementation cycle}

After the inventory and evaluation, the tool was implemented in two classrooms (out of four). In total 16 parents were invited to the information meeting, of which nine parents came, seven mothers and two fathers. They received information about the study and the manual for the tool, the contract was discussed, and they were assisted in downloading and accessing the tool. After this meeting, parents should have had access to their group bulletin board so they could upload content, inspired by the themes of the preschool (e.g., the theme "family"). However, during the implementation of the tool, many barriers and issues emerged that hindered the parents in accessing and using the tool. These issues are listed below and guided the improvements for the next iteration.

Linguistic and educational barriers. Parents' knowledge of Dutch was even more limited than we expected. The invitation letter, manual, and information meeting, in which only the Dutch language was used, were too difficult for most of the parents. As a result, parents did not fully understand the information about the study and

2 A popular messaging app that can be used to send messages, photos, videos and other files.

3 A digital school white board that teachers can use for ICT purposes. 
were unable to download and use the tool. For the second iteration, the invitation letter and the manual were translated into English, Turkish, and Standard-Arabic. Furthermore, Turkish, Standard-Arabic and Berber speaking assistants helped during the information meeting to ensure that all parents understood the information.

Cultural barriers. It turned out that parents did not have much contact with each other outside the preschool, especially if parents had different cultural backgrounds. Therefore, they were not used to to share personal experiences with other parents or with the teacher, and also not open to do this. Second, during the information meeting, the issue of gender arose, since some mothers were not comfortable with being in the same room with men they did not know. When adapting the implementation, it was decided together with the core team that the themes on the bulletin board should not be too personal (e.g. autumn is less personal than family), and that the teachers should upload content on the padlet first to show the feasibility and possibilities of the tool (i.e., modelling), and to encourage the parents to use it as well.

Technical barriers. During the information meeting, several technical issues emerged. Many parents did not have a 3G/4G internet connection on their smartphone; they tended to use only Wi-Fi connections. The preschool, however, did not offer free Wi-Fi to the parents, so they were unable to download the tool and to ask questions regarding the tool during the information meeting. Moreover, some parents could not recall their own e-mail address, so it was not possible to create a personal account for them on the tool. For the second iteration, we established an internet connection during the information meeting, so the parents could directly download the tool, and new e-mail addresses were created on the spot for the parents who did not have an e-mail address or could not recall their personal email address.

\subsection{Phase three: Second implementation cycle and analyses}

In phase three, the second implementation, two other classrooms also participated, in addition to the two previous classrooms. In total 16 out of 18 parents of the two new classrooms were invited to the information meeting by means of letter in all relevant languages. Two parents were not invited because one child would go to primary school soon and the other child's family had planned to move house to another neighbourhood soon. Eight parents, only mothers, came to the meeting and were provided with the improved manual and received information in their own language from multilingual research assistants. During the information meeting, mothers of the two new classrooms also filled out the parent survey. Since the other two classrooms already participated in the first implementation of this DBR study, only the mothers from the two new classrooms filled out the survey. During this phase, content analyses of uploaded content and classroom observations were conducted in the two new classrooms. Parents from the previous classrooms participated in an improved information meeting and continued with their own padlets, but it was 
72 decided to focus on the two new classrooms for the analyses. All experiences from the four classrooms were taken into account for the evaluation phase. Despite the relatively low number of mothers attending the meeting, the second cycle of implementation was more successful than the first cycle since more parents understood the aims of the tool and afterwards accessed and used the tool. However, again some issues emerged (e.g., lack of thorough intercultural focus on part of the teachers) or remained (e.g., hesitance of the parents to share experiences with each other), which will be discussed below.

Parent survey results. In total, nine mothers $\left(M_{\text {age }}=36.11\right.$ years, 4 from classroom $A$ and 5 from classroom $B$ ) filled out the questionnaire; eight mothers during the information meeting and one mother afterwards. Two mothers were second-generation migrants from Turkey and Morocco. The other seven mothers were first-generation migrants and born in Turkey (one mother), India (three mothers) or Morocco (three mothers), and migrated to the Netherlands between 1976 and 2015. Eight mothers stated that they used multiple languages at home, including both the mother language and Dutch. There was a large variation in education level. Two mothers did not finish primary school and two mothers obtained a Master's degree. Table 2 shows the descriptive results for the three scales on the communication and relationship with the preschool, parental participation at the preschool, and the provision of stimulating activities in the home environment.

Table 2 Results of parent questionnaire $(n=9)$

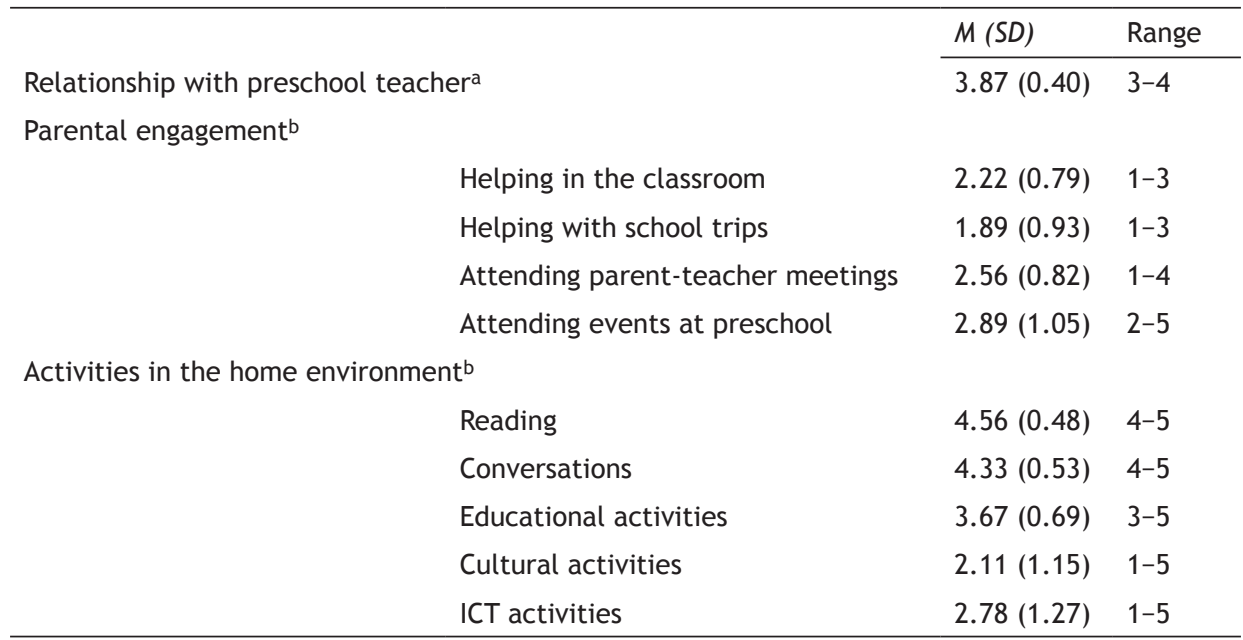

Notes: a Answer scale 1-4, b Answer scale 1-5

The scale Communication and Relation with the preschool consisted of five statements (e.g., My child's teacher sees me as an important partner of the preschool), measured with a four-point scale, ranging from disagree (1) to agree (4). When mothers scored higher, they were more positive about the relationship. On average, mothers were very positive about the relationship, showing a low variation. 
Parental engagement was measured by asking the mothers how often they partici-

pated in four parent-preschool activities (e.g., helping in the classroom, by reading to the children or cleaning the toys). This was measured by a five-point frequency scale, ranging from never (1) to more than once a month (5). There was large variation between the different items and between the mothers. The mothers scored lowest on the item helping with school trips and highest on the item attending events at the preschool. In addition, some mothers indicated that they were never engaged in preschool activities, while other mothers indicated that they participated at least three to five times a year. For Activities in the home environment, the frequency of and language use during five parent-child activities (e.g., shared reading) was measured on a five-point scale, ranging from never or rarely (1) to everyday (5). Mothers scored quite high on reading and conversation activities, with relatively low variation. In addition, all mothers stated that multiple languages were used during these activities; both the mother tongue and Dutch, or even English (for the Indian mothers). There was more variation between the mothers regarding the educational activities item, and mothers indicated that Dutch was used more than the mother language during these activities. In contrast, the mother language was mostly used during cultural activities. There was a large variation between the mothers in performing ICT activities with their children. Some mothers reported to use ICT in their activities with their children every day, while other mothers answered that they never did this. Both the mother language, Dutch, and English were used for these activities.

Next to the three scales, we asked the mothers in the survey how they perceived the attention at the preschool for intercultural and/or multilingual practices, and how they evaluated this. Most mothers indicated that there was some attention for multiple cultures at the preschool, and that they liked this. However, two mothers stated that there was no attention for this. This could mean that not all mothers are aware of the intercultural focus of the preschool, but also that they perceived little or no attention for their own culture and language. Five mothers indicated that there was no multilingual support at the preschool. Two mothers said that there should be more attention for this, however, the other three mothers stated that they liked the focus on the Dutch language. One mother even responded: They should learn Dutch here, they have the other languages at home!

Content analyses of the group-padlets. One month after the information meeting, content analyses of the posts on the group-padlets were conducted. Table 3 provides the user statistics from both classrooms A and B. Classroom A had eight children, of which four parents signed up for the Padlet tool after the information meeting. Three parents actively posted one or two pictures and a movie clip, the other parent was passively involved by liking and commenting on content, but not uploading herself. The preschool teacher was more active, posting 20 content items on the padlet. She posted pictures of daily activities and educational content that fitted the theme of the preschool at that moment. Classroom B consisted of ten children, of which seven parents signed up for the group-padlet. Four of these parents were actively 
74 using the tool, posting 14 items in total. The other three parents were passively involved. Also here, the teacher was more active by uploading 23 content items.

Table 3 Content analyses of the group-padlet during second iteration

\begin{tabular}{lcc}
\hline & Classroom A & Classroom B \\
\hline Children in the classroom & 8 & 10 \\
Parents who signed up for padlet & 4 & 7 \\
Parents participation on padlet & & \\
Actively involved - Uploading content & 3 & 4 \\
Passively involved - Only responding to or liking content & 1 & 3 \\
Posts by preschool teacher & 20 & 23 \\
Posts by parents & 5 & 14 \\
\hline
\end{tabular}

More content was uploaded in classroom B than in classroom A. This is probably due to the influence of the group of parents: when more parents uploaded more pictures, other parents were more inclined to do so as well. The three active parents in classroom $A$ were more hesitant to post something than the active parents in classroom B. The topics of the content did not differ per group, but differed between the teachers and parents. The teachers uploaded content that was related to the specific preschool theme during that month (e.g., how to play together, what is illness, what are the words the children learned that week), while the parents uploaded general content items that were more often related to the upcoming feasts and holidays (e.g., Saint Nicholas and Christmas). Sometimes, teachers uploaded content in different languages (Turkish, Standard Arabic, English and Dutch), to ensure that more parents would understand the meaning.

Observations in the classroom. Short observations in the classrooms were conducted to examine how teachers used the tool and its content, how the children responded to the tool and to which extent there was an intercultural focus. The observations took place on the same day in the morning between approximately $9 \mathrm{am}$ and $10 \mathrm{am}$ and were guided by a short semi-structured observation scheme (Appendix A).

Observations classroom A. Children had an active role during the activity; they were placed around the Digi board and could touch the board themselves. The teacher showed each item on the board and asked many (open and closed) questions: "Who do we see here? What were you doing?" She showed recent and older pictures on the digital tool, mainly of preschool activities. She tried to connect the pictures by repeating the educational content of that activity: "Remember this, we learned about ... and then we went to ..." One child saw her grandfather on one of the pictures and called him "grandfather" in her mother language. The teacher responded to this in Dutch, asking her to repeat that word, and a short multilingual conversation started. During the Padlet activity, the children were very enthusiastic about touching the Digi board and seeing the large pictures. They were completely focused 
on the content and wanted to tell about the pictures they recognized. The Padlet activity lasted 15 minutes.

Observations classroom B. In contrast to classroom A, children were sitting in a circle in the middle of the classroom, and there was a distance between them and the Digi board. The teacher asked many questions, mainly closed questions, and the children responded. However, the children were less actively involved compared to classroom B, and probably therefore less enthusiastic, and they did not start to tell about the pictures themselves. Hence, it did not lead to a deep mutual interaction between the teacher and the child. The teacher asked whether the children could see some similarities between the pictures and tried to emphasize the resemblance between the pictures that the parents had uploaded. The activity lasted about five minutes.

It should be noted that these two observations were only short snapshots. Nonetheless, it can be concluded that there were differences between the two preschool teachers: their use of the tool, the extent to which they tried to involve the children, the open versus more closed questions they asked, and the responses and engagement of the children. It became clear that it was difficult for the teachers to grasp the different cultural aspects of the content of the tool and to use this for intercultural educational practices.

\section{Discussion}

Schools, and especially preschools, face the challenge of establishing trustful educational partnerships with parents from diverse backgrounds. The current small-scale design study explored whether an educational digital tool, Padlet, could improve the educational partnerships between parents and a preschool in a multicultural urban neighbourhood in the Netherlands. The study followed a Design-Based Research approach to optimally adapt the tool and its implementation to the local context, and to involve all relevant stakeholders. Results from the focus group discussions with parents and teachers, the classroom observations, and the analyses of the uploaded contents showed that it was possible to use an existing digital tool in a superdiverse context by taking a bottom-up approach and adjusting the implementation of the tool to fit the local context. However, although the second implementation was more successful, the digital tool was still not used to its full potential. The group-padlets were used to some extent by both the teachers and the parents, but not enough to make a real difference for the educational partnerships, according to the core team. The content analyses showed that only around $60 \%$ percent of the parents engaged in using the tool (both actively and passively). During the last phase, a focus group discussion was held with the core team to evaluate the tool and reflect upon the entire process of the study (phases 1, 2 and 3). In addition to this, general principles regarding educational partnerships and the involvement of digital tools were generated. Below we list and discuss six implications for theory, policy, and practice that focus on strengthening educational partnerships 
76 in culturally diverse and multilingual settings for young children, and the use of innovative digital tools herein.

\subsection{Principles and implications for theory and practice}

Importance of parental awareness of the role of preschools and educational partnerships. According to the core team at the evaluation session, some parents enjoyed the tool since they could see the daily activities of their child, but they were not motivated to be more actively involved. Furthermore, it was stated that a substantial number of parents consider the preschool to be more like a daycare facility, where the parents can drop off children to play with other children, but that they do not perceive any educational benefits for their children there. This is in line with findings from other studies (Degotardi, Sweller, Fenech, \& Beath, 2018; Manigo \& Allison, 2017). Fenech (2017) stresses that preschools should build parents' understanding of the importance and quality of ECEC. If the educational opportunities of preschool are not brought to their awareness, it is plausible that parents do not feel committed to be involved at the preschool. This might be an explanation for the lower motivation of the parents to invest in the educational partnerships. As a first step, the importance of the preschool for children's development should be emphasized more strongly to these parents. This includes the possible positive effects of parents being more involved in the education. Then, as a next step, strategies can be introduced to enhance the partnership, but parents should understand the value of a partnership first.

Good start. Preschools strive for a smooth transition to primary school. This helps the child and parents to build a warm relationship with the primary schools from the very start. However, there is no smooth transition to the preschool itself, according to the core team. Vandenbroeck, Roets, and Snoeck (2009) stressed the importance of a warm welcome in the preschool setting for parents and children. They found the first few weeks prior to and following upon the start in the preschool to be crucial for creating a sense of belonging and establishing reciprocal relationships, both for children and their parents. This is related to the first principle, a warm welcome can shape parents' feelings of (importance of) being involved.

Superdiversity: intergroup relationship and sharing experiences. One of the reasons why the tool was not fully used by the parents, is the lack of strong intergroup relationships, according to the core team. Parents did not have much contact with each other inside nor outside the preschool context. Inter-ethnic group relations were virtually absent. Research has shown that a superdiverse environment can increase trust in other groups, but only if there is enough intergroup contact (Schmid, Ramiah, \& Hewstone, 2014). When intergroup relations are not strong, people are less likely to share personal experiences across groups. Moreover, we should be aware of the fact that the focus on self-expression and sharing personal thoughts and experiences with others might be a Western cultural construct (Vandenbroeck, 2007), with which migrant parents are not familiar and to which they are not imme- 
diately attracted. Therefore, it is essential that there is a sense of community within the preschool or classroom context and that parents know and trust each other, before inviting them to actively contribute and share experiences and expertise.

Strengthening the intercultural competences of teachers. Results from the observations showed that there was no clear intercultural and multilingual focus in the ICT practices of the preschool teachers, despite the intercultural and multilingual contents made available through the digital tool. According to the teachers, this can be explained on the one hand by the limited input from the parents. They stated that if more personal experiences had been shared on the tool, teachers could have used this more systematically to introduce an intercultural perspective in the classroom. On the other hand, the teachers admitted that they themselves found it difficult to seize the opportunities for enriching their education with intercultural and multilingual content. The preschool's diversity has been increasing over the last years, and this adds to the complexity of providing intercultural and multilingual practices. Therefore, the teachers would prefer a training to strengthen their intercultural competences, especially to learn to critically reflect on their own intercultural attitudes, knowledge and actions. This would help them in their work in a superdiverse environment (Deardorff, 2006).

Importance of bottom-up approaches. The current study has shown the importance of adapting both the digital tool and its implementation to the specific linguistic, cultural, and cognitive competences, needs, and wishes of all stakeholders. By giving voice to the parents in this bottom-up approach, the implementation was clearly improved. Both the parents and teachers expressed to enjoy this approach and to prefer it over a top-down approach. For instance, special attention was given to the multilingualism aspect. The tool and its implementation should be multilingual and rely on visual aids as much as possible, to increase the inclusiveness of the approach. Parents appreciated it that the tool could be adapted to their own mother language, that content was translated, that the survey was translated into different languages and that there were multilingual research assistants to support them. Note that this does not imply that ECEC settings should become fully multilingual regarding their educational practices. Results of the parent survey showed that several parents explicitly valued the emphasis on Dutch language in the preschool and used Dutch themselves for educational activities in the home environment. Some of the parents did not think it was important that children should be supported in their mother language at the preschool. Preschools should therefore collaborate with parents, to 1) understand their wishes and needs, to make an adequate adaptation and 2) to call in the expertise of parents when multilingual or cultural resources are needed.

Technological challenges and requirements. Previous studies concluded that in order to successfully implement a digital tool, certain practical and psychological factors should be taken into account, such as the attitudes of the stakeholders regarding ICT, teacher training regarding the digital tool, and a sufficiently long timeframe (Kerkaert et al., 2015; Wang et al., 2014). The current study provides some additional practical principles for ICT tools: an individual account for the digital tool 
is necessary to guarantee the privacy of data, but results of the first implementation also underscore the importance of using a simple login procedure that requires parents to login only once. Teachers could support the parents by providing them with personal e-mail addresses and accounts. Furthermore, it needs to be assured that both parents and teachers have a stable $3 \mathrm{G} / 4 \mathrm{G}$ connection or a Wi-Fi connection to be able to use the digital tool. Results of our first implementation showed that, although all parents have smartphones and regularly use ICT, this does not imply that they have access to a stable internet connection. Moreover, future research should provide a thorough training for the teachers in using the software (the digital tool) and hardware (the new Digi boards). Although the preschool teachers were confident about their ICT skills and practices, they appeared to struggle multiple times with the tool. Since it is likely that the use of ICT in (pre)schools will increase in the future, more attention should be paid to these technological factors that will eventually determine whether a digital tool can be successfully implemented.

\subsection{Conclusions}

This is, to the best of our knowledge, one of the first studies to explore whether innovative ICT-based strategies can enhance educational partnerships in a multicultural and multilingual preschool environment. The study showed the feasibility and added value of a bottom-up DBR approach to give voice to parents from diverse backgrounds and to bridge the gap between theory and practice (Laleka \& Rasheed, 2018). Given its explorative nature, there are several limitations to this study. We only included one preschool in the Netherlands, hence, the number of teachers and parents and the variety of perspectives is small and the generalizability of the results is limited. Note that the current explorative study was conducted within a short timeframe (one year from phase 1 to phase 3 ), when compared to other DBR studies focusing on implementation of digital tools. In the current study, we only had limited time to implement the tool, whereas Wang and colleagues (2014) stress the importance of a long time span to implement ICT in educational settings. Results of the fourth phase showed that there are many recommendations to improve the implementation. It is plausible that more time could have led to more improvements, more refined cycles, and therefore better results. It should be noted that the limited time for this study stresses the complex reality many early education and care settings face: They often have only little time to build a trustful educational partnership with parents, regardless of digital tools. This research provided a first step in the demonstration of the use of ICT for educational partnerships, and pointed out remaining questions and critical issues regarding the complexity of intercultural educational partnerships for future research. Although this was a small-scale study, the results underscore that a DBR methodology is a promising approach for future research on this topic. The implications outlined above can likely be transferred to other contexts to continue and further refine this innovative approach. 


\section{Acknowledgements}

The study is associated with the ISOTIS project (www.isotis.org), funded by the European Union within the Horizon 2020 framework programme (Grant agreement No. 727069). Funding for this additional DBR study was obtained from the municipality of Utrecht, the Netherlands. We want to thank the preschool organisation Spelenderwijs and the participating parents and teachers for their valuable contributions.

\section{References}

Amiel, T. , \& Reeves, T. C. (2008). Design-based research and educational technology: Rethinking technology and the research agenda. Journal of Educational Technology \& Society, 11(4), 29. Retrieved from https://www.jstor.org/stable/pdf/jeductechsoci.11.4.29 .pdf?seq=1\#page_scan_tab_contents

Anderson, T., \& Shattuck, J. (2012). Design-based research: A decade of progress in education research? Educational Researcher, 41(1), 16-25.

Banks, J. A. (2015). Cultural diversity and education. New York: Routledge.

Barnard, W. M. (2004). Parent involvement in elementary school and educational attainment. Children and Youth Services Review, 26(1), 39-62.

Blau, I., \& Hameiri, M. (2017). Ubiquitous mobile educational data management by teachers, students and parents: Does technology change school-family communication and parental involvement? Education and Information Technologies, 22(3), 1231-1247.

Bossong, L., \& Keller, H. (2018). Cross-cultural value mismatch in German day care institutions: Perspectives of migrant parents and day care teachers. International Journal of Psychology, 53, 72-80.

Broekhuizen, M., Ereky-Stevens, K., Wolf, R., \& Moser, T. (2018). Technical report parent structured interview study. Procedures, instrument development, samples, and showcases. Retrieved from: http://www. isotis.org/resources/publications/isotis-publications/final

Bronfenbrenner, U. (1979). The ecology of human development. Cambridge, MA: Harvard University Press.

Bronfenbrenner, U., \& Morris, P. A. (2006). The bioecological model of human development. In R. M. Lerner (Ed.), Handbook of child development: Vol. 1. Theoretical models of human development, 6th ed. (pp. 793-828). Hoboken, NJ: Wiley.

Brooks-Gunn, J., \& Markman, L. B. (2005). The contribution of parenting to ethnic and racial gaps in school readiness. The Future of Children, 15(1),139-168.

Byron, T. (2008). Safer children in a digital world: The report of the Byron Review: Be safe, be aware, have fun. Retrieved from https://dera.ioe.ac.uk/7332/7/Final\%20Report\%20 Bookmarked_Redacted.pdf

Carolan, B. V., \& Wasserman, S. J. (2015). Does parenting style matter? Concerted cultivation, educational expectations, and the transmission of educational advantage. Sociological Perspectives, 58(2), 168-186.

Christenson, S. L. (2004). The family-school partnership: An opportunity to promote the learning competence of all students. School Psychology Review, 33(1), 83-104.

Crozier, G., \& Davies, J. (2007). Hard to reach parents or hard to reach schools? A discussion of home-school relations, with particular reference to Bangladeshi and Pakistani parents. British Educational Research Journal, 33(3), 295-313.

Davies, N. (2004). Not just how but why: EAL and ICT in the multilingual classroom. NALDIC Quarterly, 1(4), 12-19. Retrieved from https: / / www.naldic.org.uk/Resources/NALDIC /Teaching\%20and\%20Learning/Documents/Notjusthowbutwhy.pdf 
80 Deardorff, D. K. (2006). The identification and assessment of intercultural competence as a student outcome of internationalization at institutions of higher education in the United States. Journal of Studies in International Education, 10(3), 241-266.

Degotardi, S., Sweller, N., Fenech, M., \& Beath, A. (2018). Influences on parents' child care choices: A comparative analysis of preschool and long day care users. Child \& Youth Care Forum, 47(5), 683-700.

Dusi, P. (2012). The family-school relationships in Europe: A research review. Center for Educational Policy Studies Journal, 2(1), 13-33.

De Civita, M., Pagani, L., Vitaro, F., \& Tremblay, R. E. (2004). The role of maternal educational aspirations in mediating the risk of income source on academic failure in children from persistently poor families. Children and Youth Services Review, 26(8), 749-769.

Eamon, M. K. (2002). Effects of poverty on mathematics and reading achievement of young adolescents. The Journal of Early Adolescence, 22(1), 49-74.

Epstein, J. L. (1992). School and family partnerships. In M. Aiken (Ed.), Encyclopedia of educational research, 6th ed. (pp. 1139-1151). New York: Macmillan.

Epstein, J. L. (2001). School, family, and community partnerships: Preparing educators and improving schools. Boulder, CO: Westview Press

Fan, X., \& Chen, M. (2001). Parental involvement and students' academic achievement: A meta-analysis. Educational Psychology Review, 13(1), 1-22.

Fenech, M. (2017). Building parents' understandings of early learning and quality early childhood education and care. Every Child, 23(1), 22-24. Retrieved from https: / / search.informit.com.au/documentSummary; dn=674400205944888;res=IELHSS

Gibson, M. A. (2002). The new Latino diaspora and educational policy. In S. Wortham, E. G. Murillo, \& E. T. Hamann (Eds.), Education in the new Latino diaspora: Policy and the politics of identity (pp. 241-252). Westport, CT: Ablex.

Gorp, van, K., \& Moons, C. (2014). Creating rich language environments for more than one language: A work in progress in Flemish childcare. European Journal of Applied Linguistics, 2(1), 53-78.

Grant, L. (2011). I'm a completely different person at home: using digital technologies to connect learning between home and school. Journal of Computer Assisted Learning, 27, 292-302.

Grolnick, W. S., \& Slowiaczek, M. L. (1994). Parents' involvement in children's schooling: A multidimensional conceptualization and motivational model. Child Development, 65(1), 237-252.

Halgunseth, L. C., Peterson, A., Stark, D. R., \& Moodie, S. (2009). Family engagement, diverse families, and early childhood education programs: An integrated review of the literature. National Association for the Education of Young Children. Retrieved from http://www .buildinitiative.org/portals/0/uploads/documents/resource-center/diversity-and-equity -toolkit/halgunseth.pdf

Hatzigianni, M., \& Margetts, K. (2012). 'I am very good at computers': Young children's computer use and their computer self-esteem. European Early Childhood Education Research Journal, 20, 3-20.

Hill, N. E., \& Taylor, L. C. (2004). Parental school involvement and children's academic achievement: Pragmatics and issues. Current Directions in Psychological Science, 13(4), 161-164.

Hoadley, C. M. (2004). Methodological alignment in design-based research. Educational Psychologist, 39(4), 203-212.

Hollingworth, S., Mansaray, A., Allen, K., \& Rose, A. (2011). Parents' perspectives on technology and children's learning in the home: social class and the role of the habitus. Journal of Computer Assisted Learning, 27(4), 347-360.

Holm, G., \& Zilliacus, H. (2009). Multicultural education and intercultural education: Is there a difference?. In M. Talib, J. Loima, H. Paavola, \& S. Patrikainen (Eds.), Dialogues on Diversity and Global Education (pp. 11-28). Berlin: Peter Lang.

Hoover-Dempsey, K. V., \& Sandler, H. M. (1995). Parental involvement in children's education: Why does it make a difference? Teachers College Record, 97(2), 310-331. 
Jewitt, C., \& Parashar, U. (2011). Technology and learning at home: findings from the evaluation of the Home Access Programme pilot. Journal of Computer Assisted Learning, 27(4), 303-313.

Jeynes, W. H. (2005). A meta-analysis of the relation of parental involvement to urban elementary school student academic achievement. Urban Education, 40(3), 237-269.

Kerckaert, S., Vanderlinde, R., \& Van Braak, J. (2015) The role of ICT in early childhood education: Scale development and research on ICT use and influencing factors. European Early Childhood Education Research Journal, 22(2), 183-199.

Kim, Y. (2009). Minority parental involvement and school barriers: Moving the focus away from deficiencies of parents. Educational Research Review, 4(2), 80-120.

Kraft, M. A., \& Rogers, T. (2014). Teacher-to-parent communication: Experimental evidence from a low-cost communication policy. Society for Research on Educational Effectiveness. Retrieved from https://files.eric.ed.gov/fulltext/ED563011.pdf

Lee, J. S., \& Bowen, N. K. (2006). Parent involvement, cultural capital, and the achievement gap among elementary school children. American Educational Research Journal, 43(2), 193-218.

Laleka, S. M. , \& Rasheed, K. (2018). Design-Based Research in education: A prolific approach to applied research in developing countries. Journal of Research \& Reflections in Education, 12(2), 136-154. Retrieved from http://ue.edu.pk/jrre/articles/article1.pdf

Liu, X., Toki, E. I., \& Pange, J. (2014). The use of ICT in preschool education in Greece and China: A comparative study. Procedia-Social and Behavioral Sciences, 112, 1167-1176.

Manigo, C., \& Allison, R. (2017). Does pre-school education matter? Understanding the lived experiences of parents and their perceptions of preschool education. Teacher Educators' Journal, 10, 5-42. Retrieved from https://files.eric.ed.gov/fulltext/EJ1138778.pdf

Meissner, F., \& Vertovec, S. (2015). Comparing super-diversity. Ethnic and Racial Studies, 38(4), 541-555.

Michel, M. C., \& Kuiken, F. (2014). Language at preschool in Europe: Early years professionals in the spotlight. European Journal of Applied Linguistics, 2(1), 1-26.

OECD/European Union (2015). Indicators of Immigrant Integration 2015: Settling In. Paris: OECD Publishing. doi: 10.2785/13779

OECD (2013). Education at a Glance 2013: OECD Indicators. Paris: OECD Publishing. doi: 10.1787/eag-2013-en

Oostdam, R., \& Hooge, E. (2013). Making the difference with active parenting; forming educational partnerships between parents and schools. European Journal of Psychology of Education, 28(2), 337-351.

Palts, K., \& Kalmus, V. (2015). Digital channels in teacher-parent communication: The case of Estonia. International Journal of Education and Development using Information and Communication Technology, 11(3), 65-81.

Petrogiannis, K. (2010). The relationship between perceived preparedness for computer use and other psychological constructs among kindergarten teachers with and without computer experience in Greece. Journal of Information Technology Impact, 10(2), 99-110.

Plowman, L., Stevenson, O., Stephen, C., \& McPake, J. (2012). Preschool children's learning with technology at home. Computers \& Education, 59(1), 30-37.

Prins, D., Wienke, D., \& van Rooijen, K. (2013). Ouderbetrokkenheid in het onderwijs. Nederlands Jeugd Instituut. Retrieved from https://www.nji.nl/nl/Download-NJi/KOJ-Ouderbetrokkenheid.pdf

Putnam, R. D. (2007). E pluribus unum: Diversity and community in the twenty-first century: The 2006 Johan Skytte Prize Lecture. Scandinavian Political Studies, 30(2), 137-174.

Respler-Herman, M., Mowder, B. A., Yasik, A. E., \& Shamah, R. (2012). Parenting beliefs, parental stress, and social support relationships. Journal of Child and Family Studies, 21(2), 190-198.

Rimm-Kaufman, S. E., \& Pianta, R. C. (2005). Family-school communication in preschool and kindergarten in the context of a relationship-enhancing intervention. Early Education and Development, 16(3), 287-316. 
82 Rosa, E. M., \& Tudge, J. (2013). Urie Bronfenbrenner's theory of human development: Its evolution from ecology to bioecology. Journal of Family Theory \& Review, 5(4), 243-258.

Schmid, K., Ramiah, A. A., \& Hewstone, M. (2014). Neighborhood ethnic diversity and trust: The role of intergroup contact and perceived threat. Psychological Science, 25(3), 665-674.

Schreiber, J. B. (2002). Institutional and student factors and their influence on advanced mathematics achievement. The Journal of Educational Research, 95(5), 274-286.

Selwyn, N., Banaji, S., Hadjithoma-Garstka, C., \& Clark, W. (2011). Providing a platform for parents? Exploring the nature of parental engagement with school learning platforms. Journal of Computer Assisted Learning, 27(4), 314-323.

Semke, C. A., \& Sheridan, S. M. (2012). Family-School connections in rural educational settings: A systematic review of the empirical literature. School Community Journal, 22(1), 21-47. Retrieved from https://files.eric.ed.gov/fulltext/EJ974684.pdf

Sandoval, W. (2014). Conjecture mapping: An approach to systematic educational design research. Journal of the Learning Sciences, 23(1), 18-36.

Tashakkori, A., \& Teddlie, C. (2006). Mixed methodology: Combining qualitative and quantitative approaches. Thousand Oaks, CA: Sage.

Tayler, C. (2006). Challenging partnerships in Australian early childhood education. Early Years, 26(3), 249-265.

Temple, J. A., Reynolds, A. J., \& Miedel, W. T. (2000). Can early intervention prevent high school dropout? Evidence from the Chicago Child-Parent Centers. Urban Education, 35(1), 31-56.

Thompson, B. C., Mazer, J. P., \& Flood Grady, E. (2015). The changing nature of parent-teacher communication: Mode selection in the smartphone era. Communication Education, 64(2), 187-207.

Vandenbroeck, M. (2007). Beyond anti-bias education: changing conceptions of diversity and equity in European early childhood education. European Early Childhood Education Research Journal, 15(1), 21-35.

Vandenbroeck, M., Roets, G., \& Snoeck, A. (2009). Immigrant mothers crossing borders: Nomadic identities and multiple belongings in early childhood education. European Early Childhood Education Research Journal, 17(2), 203-216.

Van Laere, E., Rosiers, K., Van Avermaet, P., Slembrouck, S., \& Van Braak, J. (2017). What can technology offer to linguistically diverse classrooms? Using multilingual content in a computer-based learning environment for primary education. Journal of Multilingual and Multicultural Development, 38(2), 97-112.

Wang, M. T., \& Degol, J. (2016). School climate: A review of the construct, measurement, and impact on student outcomes. Educational Psychology Review, 28(2), 315-352.

Wang, S. K., Hsu, H. Y., Reeves, T. C., \& Coster, D. C. (2014). Professional development to enhance teachers' practices in using information and communication technologies (ICTs) as cognitive tools: Lessons learned from a design-based research study. Computers \& Education, 79, 101-115.

Webb, S. (2006). Can ICT reduce social exclusion? The case of an adults' English language learning programme. British Educational Research Journal, 32(3), 481-507.

Wit, C. de (2005). Ouders als educatieve partner. Een handreiking voor scholen. Den Haag: Q*Primair.

Young, A. S. (2014). Working with super-diversity in Strasbourg pre-schools: Strengthening the role of teaching support staff. European Journal of Applied Linguistics, 2, 27-52.

Young, A., \& Hélot, C. (2007). Parent Power: Parents as a linguistic and cultural resource at school. In A. Camilleri Grima (Ed.), Promoting linguistic diversity and whole-school development (pp. 17-32). Strasbourg, Graz, Austria: Council of Europe Publishing. 
Ryanne Francot, MSc.

Utrecht University, Faculty of Social Sciences Heidelberglaan 1, 3584 CS Utrecht, The Netherlands

R.J.R.M.Francot@uu.nl

Dr. Martine Broekhuizen

Utrecht University, Faculty of Social Sciences Heidelberglaan 1, 3584 CS Utrecht, The Netherlands

M.L.Broekhuizen@uu.nl

Prof. dr. Paul Leseman

Utrecht University, Faculty of Social Sciences Heidelberglaan 1, 3584 CS Utrecht, The Netherlands

P.P.M.Leseman@uu.nl

\section{Appendix A.}

Semi-Structured Observation Scheme for Classroom Observations

\begin{tabular}{ll}
\hline Content Related & Which pictures are described? \\
\hline How are the pictures described? & Is there attention for the different cultures? \\
Is there attention for the different languages? & Are the relations or similarities between the \\
& pictures described? \\
& How is the content from the digital tool \\
integrated in the practices?
\end{tabular}

